Article

\title{
Preparation and Identification of Optimal Synthesis Conditions for a Novel Alkaline Anion-Exchange Membrane
}

\author{
Aitor Marcos-Madrazo ${ }^{1}$, Clara Casado-Coterillo ${ }^{1, *(\mathbb{D})}$, Leticia García-Cruz ${ }^{2}$, Jesús Iniesta ${ }^{2}$, \\ Laura Simonelli $^{3}$, Víctor Sebastián ${ }^{4,5}$ (D), María del Mar Encabo-Berzosa ${ }^{4,5}$, Manuel Arruebo ${ }^{4,5}$ \\ and Ángel Irabien 1 (D) \\ 1 Department of Chemical and Biomolecular Engineering, Universidad de Cantabria, 39005 Santander, Spain; \\ marcosma@unican.es (A.M.-M.); irabienj@unican.es (Á.I.) \\ 2 Department of Physical Chemistry and Institute of Electrochemistry, University of Alicante, 03080 Alicante, \\ Spain; leticia.garcia@ua.es (L.G.-C.); jesus.iniesta@ua.es (J.I.) \\ 3 CELLS-ALBA Synchrotron Radiation Facility, Carrer de la Llum 2-26, 08290 Cerdanyola del Vallès, \\ Barcelona, Spain; lsimonelli@cells.es \\ 4 Department of Chemical and Environmental Engineering, Instituto de Nanociencia de Aragón, \\ Universidad de Zaragoza, 50018 Zaragoza, Spain; victorse@unizar.es (V.S.); mmar@unizar.es (M.d.M.E.-B.); \\ arruebom@unizar.es (M.A.) \\ 5 Networking Research Center on Bioengineering, Biomaterials and Nanomedicine, CIBER-BBN, \\ 28029 Madrid, Spain \\ * Correspondence: casadoc@unican.es; Tel.: +34-942-206777
}

Received: 6 July 2018; Accepted: 9 August 2018; Published: 13 August 2018

\begin{abstract}
The physicochemical and mechanical properties of new alkaline anion-exchange membranes (AAEMs) based on chitosan (CS) and poly(vinyl alcohol) (PVA) polymers doped with unsupported copper nanoparticles (NPs) and copper exchanged over different porous materials were investigated regarding ion-exchange capacity (IEC), $\mathrm{OH}^{-}$conductivity, water uptake (WU), water vapor permeability (WVP), and thermal and mechanical resistance. The influence of the type of filler included in different morphologies and filler loading has been explored using copper exchanged materials such as the layered porous titanosilicate AM-4, layered stannosilicate UZAR-S3, and zeolites Y, MOR, and BEA. Compared to commercially available anion-exchange membranes, the best performing membranes in terms of WU, IEC, $\mathrm{OH}^{-}$conductivity and WVP in this study were those containing $10 \mathrm{wt} \%$ of $\mathrm{Cu}-\mathrm{AM}-4$ and $\mathrm{Cu}-\mathrm{UZAR}-\mathrm{S} 3$, although $10 \mathrm{wt} \% \mathrm{Cu}-\mathrm{MOR}$ provided better mechanical strength at close values of WVP and anion conductivity. It was also observed that when $\mathrm{Cu}$ was exchanged in a porous silicate matrix, its oxidation state was lower than when embedded as unsupported metal NPs. In addition, the statistical analysis of variance determined that the electrochemical properties of the membranes were noticeably affected by both the type and filler loading, and influenced also by the copper oxidation state and content in the membrane, but their hydrophilic properties were more affected by the polymers. The largest significant effects were noticed on the water sorption and transport properties, which gives scope for the design of AAEMs for electrochemical and water treatment applications.
\end{abstract}

Keywords: ion exchange membranes; renewable and economic polymers; copper based fillers; ANOVA; regression analysis; water vapor permeability (WVP); anion conductivity; X-ray absorption near edge structure (XANES) 


\section{Introduction}

Alkaline anion-exchange membranes (AAEMs) are gaining relevance in the electrochemistry field [1], presenting a wide range of sustainable applications. AAEMs are generally designed to conduct anions preferentially and they are usually prepared from positively charged polyelectrolytes. The major challenges in the development of AAEMs are the improvement in their commonly low $\mathrm{OH}^{-}$conductivity and the required water management to maintain $\mathrm{OH}^{-}$transport from cathode to anode [2,3], whose regulation has been attempted by many procedures such as developing specific flow configurations [4], coating hydrophobic layers on hydrophilic AAEMs [5], ion-exchanging metallic ions in conductive polymers [6], and so on.

Currently, the preparation of AAEMs usually involves the modification of pristine polymers or the direct polymerization of functionalized monomers, where the large amount of organic solvents used during both the reaction and membrane formation processes brings toxicity risks to the environment. Hence, to achieve industrial-scale manufacture, it is important to develop simple, rapid, and environmentally friendly methods for preparing AAEMs [7]. Employing low-cost or renewable polymers, as well as nontoxic inorganic fillers in the synthesis of new membranes is also a way of improving the sustainability of the process. To this end, chitosan (CS) and poly(vinyl) alcohol (PVA) constitute some of the renewable or low-cost alternative in AAEMs for electrochemical processes because its high hydrophilicity and ion exchange capacity, controllable permeability, and consequent energy savings [8,9]. Equimolar blends of CS and PVA were previously proposed as alkaline resistant AAEMs [10], in pervaporation [11,12] and adsorption processes [13].

The swelling by water or any other aqueous media in hydrophilic polymer membranes such as CS:PVA membranes can be further tuned-up by their hybridization with copper nanoparticles (NPs) $[14,15]$. However, the mechanical stability and reproducible fabrication can be compromised by the interactions of those metal nanoparticles with the ionic charged groups of the polymer chains $[15,16]$. The incorporation of inorganic moieties in a polymer matrix may increase the mechanical integrity of the membranes [17]. Inorganic moieties can be incorporated in a polymer matrix by: (i) in situ growth of unsupported NPs $[16,18]$; (ii) introduction of separately prepared or commercial unsupported metal NPs [19], and ion-exchanging the metal cation onto ion-exchangeable materials such as layered titanosilicates [20], or three-dimensional zeolite particles [21].

In this work, we optimized the synthesis of AAEMs prepared from CS:PVA, embedded with inorganic fillers: metal NPs, in the ion-exchangeable nanoporous layered AM-4 titanosilicate and the UZAR-S3 stannosilicate, as well as in different zeolite topologies as Y, MOR, and BEA to improve the membrane properties. The membrane performance was explored in terms of anion-exchange capacity (IEC), hydroxide anion conductivity, water vapor permeability (WVP), and water uptake (WU), and they were compared with those retrieved from a commercial anion exchange membrane.

\section{Materials and Methods}

The polymers employed in this study were chitosan (CS, coarse ground flakes and powder) with molecular weight between 310,000-375,000 Da and 75\% deacetylation degree, and poly(vinyl) alcohol (PVA, powder, $99+\%$ hydrolyzed) with molecular weight from 85,000-120,000 Da, both obtained from Sigma-Aldrich, Madrid, Spain, and used as received. Commercial copper nanoparticles $(60-80 \mathrm{~nm}$ particle size, Sigma-Aldrich, Spain) were used as one of the fillers. The commercial FAA-3 AEM was supplied by Fumatech BWT GmbH (Bietigheim-Bissingen, Germany) and treated in the same way as the prepared membranes for comparison purposes.

\subsection{Layered Silicates}

The reagents used for the layered materials synthesis were: sodium silicate solution $\left(2 \mathrm{wt} \% \mathrm{SiO}_{2}\right.$, $8 \mathrm{wt} \% \mathrm{Na}_{2} \mathrm{O}$, Merck, Madrid, Spain), titanium(IV) oxide, and tin(II) chloride dihydrate (both from 
Sigma Aldrich, Spain). Other chemicals were acetic acid (glacial), hydrochloric acid (37\%), and sodium hydroxide (pellets), all of them obtained from PANREAC, Barcelona, Spain, and used as received.

The synthesis of layered porous silicates by hydrothermal crystallization was reported elsewhere [22,23]. For the preparation of AM-4 titanosilicate, sodium silicate solution (10.05 g) was mixed with $\mathrm{NaOH}(1.42 \mathrm{~g})$ and deionized water $(6.54 \mathrm{~mL})$. Then, $\mathrm{TiO}_{2}$ anatase $(0.77 \mathrm{~g})$ was added, rendering a gel with $\mathrm{pH}$ 12.1. The gel was seeded on previously synthesized AM-4 (0.08 g) (corresponding to the $0.45 \mathrm{wt} \%$ of the mixture) in order to favor the crystallization. After mixing for $1 \mathrm{~h}$, the gel was poured into Teflon-lined autoclaves and heated at $230^{\circ} \mathrm{C}$ for $6 \mathrm{~h}$. The typical amount of AM-4 obtained from one synthesis batch was $2 \mathrm{~g}$.

For the UZAR-S3 stannosilicate synthesis [23], the same silicate source as the one used for the AM-4 preparation was employed. The tin source was then added as tin(II) chloride dehydrate $(2.41 \mathrm{~g})$ to the mixture, and stirred for $90 \mathrm{~min}$. The gel was introduced in a Teflon-lined autoclave and heated at $230{ }^{\circ} \mathrm{C}$ for $96 \mathrm{~h}$. The typical amount of UZAR-S3 collected product was $4 \mathrm{~g}$.

After both syntheses, the solid obtained was washed and filtered three times with $50 \mathrm{~mL}$ of deionized water each and dried at $70{ }^{\circ} \mathrm{C}$.

The addition of $\mathrm{Cu}$ to the layered silicates was performed by an ion-exchange process to replace de $\mathrm{Na}^{+}$ions with $\mathrm{Cu}^{2+}$, as previously reported [20]. The amount of layered material incorporated in the ion-exchange process was $0.5 \mathrm{~g}$. A $10 \mathrm{mM}$ solution of $\mathrm{Cu}^{2+}$ was prepared by dissolving $\mathrm{Cu}$ (II) nitrate in $50 \mathrm{~mL}$ of water. The layered material and the $\mathrm{Cu}^{2+}$ solution were mixed in a beaker under continuous stirring. The process was controlled by measuring the $\mathrm{pH}$ of the mixture every $10 \mathrm{~s}$ until reaching the equilibrium (Figure $\mathrm{S} 1$ in the Supporting Information). Although for both layered materials the $\mathrm{pH}$ was stabilized almost immediately, the process was maintained for $10 \mathrm{~min}$ to assure that the equilibrium was reached. The differences in the final value of the $\mathrm{pH}$ after the exchange process with AM-4 and UZAR-S3 are shown in Figure S1 and they might indicate that the ion exchange was more efficient when using the former material.

\subsection{Zeolites}

Fresh and metal-exchanged zeolites were prepared from $\mathrm{Na}^{+}$or $\mathrm{NH}_{4}{ }^{+}$zeolites supplied by Zeolyst Int. (Products CBV10A (MOR), CBV100 (zeolite Y), and CP814E (BEA)) with Si/ Al ratios equal to 5.1, 13, and 25, respectively, following the work previously reported by Abu-Zied [21].

\subsection{Membrane Preparation}

Membranes were prepared from equimolar blends of CS and PVA dissolved in acidic aqueous media and solution casted as reported elsewhere [10]. Mixed matrix membranes (MMMs) were prepared by adding different inorganic filler loadings from 5 to $15 \mathrm{wt} \%$ of the total solid to the polymer solution. The three types of inorganic fillers selected were: unsupported $\mathrm{Cu}$ NPs, Cu-exchanged in the layered silicates, and $\mathrm{Cu}$-exchanged in the 3D zeolites. The $\mathrm{Cu}$-containing fillers were dispersed in $2 \mathrm{~mL}$ of water prior to their introduction in the polymer blend solution, stirred for another $24 \mathrm{~h}$, and degassed in an ultrasonic bath before casting on a glass plate. The solutions were left to dry at room temperature in a fume hood. Once the solvent was fully evaporated, a post-treatment was applied to the membranes for their activation, by immersing them in a $1 \mathrm{M} \mathrm{NaOH}$ solution for $1 \mathrm{~h}$ and afterwards rinsed at least 3-5 times with plenty of ultrapure water till $\mathrm{pH}$ was around 5.5.

\subsection{Membrane Characterization}

The viscosity of polymeric solutions was measured by a viscometer Fungilab (Barcelona, Spain) at $25^{\circ} \mathrm{C}$.

The real copper content of the inorganic fillers was measured by atomic absorption in a 3110 Perkin Elmer spectrophotometer (Madrid, Spain).

Membrane thicknesses were measured using a digital micrometer IP-65, with an accuracy of $0.001 \mathrm{~mm}$ (Mitutoyo Corp., Kawasaki, Japan) at several points of each membrane sample. 
Water uptake (WU) was calculated using the Equation (1) that takes into account the high hydrophilic character of PVA in the hydrophilicity of the hybrid membranes [24].

$$
\mathrm{WU}(\%)=\frac{W_{\text {wet }}-W_{d r y}}{\frac{W_{\text {wet }}-W_{d r y}}{1.0}+\frac{W_{d r y}}{1.3}} \cdot 100
$$

where $W_{\text {wet }}$ and $W_{d r y}$ were the wet and dry weight of the membrane pieces, respectively, 1.0 and 1.3 were the correction factors for water and PVA densities, respectively. The three samples were weighted after being immersed for $24 \mathrm{~h}$ in water to obtain $W_{\text {wet }}$. The excess of water from the membrane surface was removed by tapping with filter paper. Samples were left to dry at room temperature and then weighted for the measurement of $W_{d r y}$.

Ion-exchange capacity (IEC) is defined as mmol of ion exchangeable groups per $1 \mathrm{~g}$ of membrane [25]. This property was determined by an acid-base back-titration procedure, slightly modified from the previously used method in our laboratory to increase reproducibility and reduce the risk of dissolution and $\mathrm{CO}_{2}$ contamination $[10,26]$; no differences were observed by lengthening the $\mathrm{OH}^{-}$activation step from 1 to $24 \mathrm{~h}$ in the results obtained. The $\mathrm{OH}^{-}$activated samples were immersed in $0.01 \mathrm{M} \mathrm{HCl}(20 \mathrm{~mL})$ for $24 \mathrm{~h}$ to exchange their mobile anions with $\mathrm{Cl}^{-}$. The $\mathrm{HCl}$ solution [25] was back-titrated with a standardized $0.01 \mathrm{M} \mathrm{NaOH}$ solution using phenolphthalein as indicator and the IEC was calculated by Equation (2) as follows:

$$
\mathrm{IEC}(\mathrm{mmol} / \mathrm{g})=\frac{\left(V_{\mathrm{NaOH}}-V_{\mathrm{NaOH} i}\right) \cdot C_{\mathrm{NaOH}}}{W_{d r y}}
$$

where $V_{\mathrm{NaOH}}$ was the volume of $\mathrm{NaOH}$ spent in the titration of $10 \mathrm{~mL}$ of $\mathrm{HCl}$ solution and $V_{\mathrm{NaOH}} i$ was the volume of $\mathrm{NaOH}$ spent in the titration of $10 \mathrm{~mL}$ of the $\mathrm{HCl}$ solution after the anion exchange with the membrane. $C_{\mathrm{NaOH}}$ was the molar concentration of the solution employed for the titration. WU and IEC were measured for three different membrane samples to assure reproducibility.

Anion conductivity was measured by electrochemical impedance spectroscopy (EIS) [27], using a VMP3 multichannel potentiostat-galvanostat (Biologic, Seyssinet-Pariset, France). A membrane sample of $1.13 \mathrm{~cm}^{2}$ was placed between the electrodes. The impedance experiments were measured over the $3 \mathrm{MHz}-100 \mathrm{~Hz}$ frequency range at open circuit potential. Experiments were carried out at a controlled temperature of $25 \pm 3^{\circ} \mathrm{C}$. Before each measurement, the membranes were activated again in $1 \mathrm{M} \mathrm{NaOH}$ solution and rinsed thoroughly with ultrapure $(18.2 \mathrm{M} \Omega)$ water. Anion conductivity was calculated by Equation (3),

$$
\sigma=\frac{L}{R a}
$$

where $L$ was the membrane thickness $(\mathrm{cm}), a$ the surface of the membrane exposed to the electric field $\left(\mathrm{cm}^{2}\right)$, and $R$ the membrane resistance $(\Omega)$ obtained from Nyquist and Bode diagrams (not shown).

Thermogravimetric analyses (DTA-TGA) were performed with a thermobalance (DTG- $60 \mathrm{H}$, Shimadzu, Kyoto, Japan) in air and $\mathrm{N}_{2}(50 \mathrm{~mL} / \mathrm{min})$. Membrane samples between 1 and $5 \mathrm{mg}$ were placed in an alumina pan. The samples were heated up to $650{ }^{\circ} \mathrm{C}$ at a rate of $10^{\circ} \mathrm{C} / \mathrm{min}$ in air and in nitrogen. The water content (WC) bound to the polymeric matrix was determined from the TGA curves, expressed in wt \%. Two values of mass were taken from the curves, $m_{1}$ and $m_{2}$, corresponding to temperatures $T_{1}$ and $T_{2}$ (the range of temperature in which a remarkable drop in mass was observed, between $119^{\circ} \mathrm{C}$ and the decomposition temperature). WC was calculated using the equation reported by Franck-Lackaze et al. [28],

$$
\mathrm{WC}(\%)=100 \cdot\left(1-\frac{m_{1}}{m_{2}}\right)
$$

Water vapor permeability (WVP) was measured following the ASTM E96-05 method, as modified by McHugh et al. [29], and described by Hosseini et al. [30]. This method consisted in sealing the membrane sample between the openings of two glass cups with a diameter of $39 \mathrm{~mm}$, one of them 
was filled with $6 \mathrm{~mL}$ of distilled water, which is equivalent to a $100 \% \mathrm{RH}$ at $20{ }^{\circ} \mathrm{C}$. The system was placed in a desiccator at room temperature and $0 \% \mathrm{RH}$. The water that permeated through the membrane was controlled by measuring the weight of the system every $2 \mathrm{~h}$, until $10 \mathrm{~h}$. Weight loss was plotted versus time, and the slope obtained $\left(R^{2}>0.99\right)$ was divided by the membrane exposed area to calculate the water vapor transmission rate WVTR $\left(\mathrm{g} / \mathrm{h} \mathrm{m}^{2}\right)$. WVP was calculated by applying the following equation

$$
\mathrm{WVP}\left(\mathrm{g} \mathrm{mm} / \mathrm{kPa} \mathrm{h} \mathrm{m}{ }^{2}\right)=\frac{\mathrm{WVTR} \cdot L}{\Delta p}
$$

where $\Delta p$ was the water vapor pressure difference $(\mathrm{kPa})$ between the two sides of the membrane, which was equal to $2.337 \mathrm{kPa}$ for the given difference in $\mathrm{RH}$ between both sides and $L$ was the membrane thickness in $\mathrm{mm}$. The measurement of this property was performed twice for each membrane sample.

TEM images of selected membrane samples were observed using a TECNAI T20 microscope (Instituto de Nanociencia de Aragón, Zaragoza, Spain) operating at $200 \mathrm{kV}$. Membranes were fixed in epoxy resin and cut with an Ultramicrotome (Leica EM UC7, Instituto de Nanociencia de Aragón, Zaragoza, Spain) equipped with a diamond knife. A $50 \mathrm{~nm}$ thick slice was deposited on a holey carbon copper grid before electronic observation.

The mechanical resistance of the membranes was measured by the tensile strength and the elongation at break in a Universal Testing Machine (Instron 8874, (Instituto de Nanociencia de Aragón, Zaragoza, Spain) with a head load up to $5 \mathrm{kN}$ and an axial velocity of $5 \mathrm{~mm} / \mathrm{min}$. An average of $2-7$ samples, cut to specified dimensions, per membrane composition, were measured in humid conditions.

The crystalline structure of the samples was investigated by means of room temperature XRD. The patterns were collected on a Philips X'Pert PRO MPD diffractometer (CITIMAC-Universidad de Cantabria, Santander, Spain) operating at $45 \mathrm{kV}$ and $40 \mathrm{~mA}$, equipped with a germanium Johansson monochromator that provides $\mathrm{Cu} \mathrm{K} \alpha_{1}$ radiation $(\lambda=1.5406 \AA)$, and a PIXcel solid-angle detector, at a step of $0.05^{\circ}$.

XPS were recorded on a K-Alpha Thermo Scientific spectrometer using AlK $\alpha(1486.6 \mathrm{eV})$ radiation, monochromatized by a twin crystal monochromator, and yielded a focused $X$ ray spot with a diameter of $400 \mathrm{~mm}$, at $3 \mathrm{~mA}$ and $12 \mathrm{kV}$. Deconvolution of the XPS spectra was carried out using a Shirley background.

In order to obtain a more detailed speciation of the metal loading in the membranes X-ray absorption spectra were acquired at $\mathrm{Cu}$ K-edge $(8905.3 \mathrm{eV})$ at CLAESS, the X-ray absorption spectroscopy beamline of ALBA synchrotron (Barcelona, Spain) [31]. Data normalization and linear combination were done using the Athena free software (Demeter 0.9.25)) [32].

\subsection{Analysis of Variance: Effects of the Preparation Variables in Membrane Properties}

To study the possible effect and interaction of the preparation variables in the properties measured for the membranes, a statistical analysis was performed on the operation conditions considered in this work. The experimental factors analyzed were the type of filler, the filler loading, and the Cu content in the membrane matrix. The properties studied in this analysis were: IEC, conductivity, WU, WVP, thickness and mechanical properties, TS, and elongation at break. The 3-factor analysis of variance (ANOVA) was applied to all the replicate data measured for the different properties to analyze the interaction between them. The effects of the filler type and loading along with the $\mathrm{Cu}$ content in the membrane on the properties measured in this work were determined by comparing the F-statistic with its critical value, with a 95\% confidence level $(\alpha=0.05)$.

\section{Results and Discussion}

\subsection{Physico-Chemical Characterization of the Membranes}

Table 1 contains the list of the membranes studied in this work. The viscosity of the dispersion of $\mathrm{Cu} / \mathrm{CS}: \mathrm{PVA}$ solution was reduced $97 \%$ from the pure polymer blend, as presented in Table 1 , 
complicating the casting of these membranes. Consequently, the membranes filled with unsupported $\mathrm{Cu}$ NPs, due to the low solution viscosity, had to be cast on plastic $12 \mathrm{~cm} \times 12 \mathrm{~cm}$ Petri dishes instead of on glass plates as for the rest of the membranes. The presence of unsupported $\mathrm{Cu}$ NPs affected not only the viscosity of the polymeric solution, but also its color. It was remarkable that the two $\mathrm{NP}$ loadings studied modified diversely the color of the resulting membrane, being the $5 \mathrm{Cu} / \mathrm{CS}$ :PVA membrane dark blue while the 10Cu/CS:PVA one was green.

Table 1. Description of the membranes prepared.

\begin{tabular}{|c|c|c|c|c|c|}
\hline Membrane $^{1}$ & $\begin{array}{l}\text { Filler Loading } \\
\text { (wt \%) }\end{array}$ & $\begin{array}{l}\text { Viscosity } \\
\text { (mPa s) }\end{array}$ & $\begin{array}{l}\text { Color of } \\
\text { Solution }\end{array}$ & $\begin{array}{c}\text { Color of } \\
\text { Membrane }\end{array}$ & $\begin{array}{c}\mathrm{Cu} \\
(\mathrm{wt} \%)\end{array}$ \\
\hline CS:PVA & 0 & 223 & Yellowish & Transparent & 0 \\
\hline 1Cu/CS:PVA & 1 & 19.8 & Grey/green & Light blue & 1 \\
\hline 5Cu/CS:PVA & 5 & 7.80 & Grey/green & Dark blue & 5 \\
\hline 10Cu/CS:PVA & 10 & 4.50 & Grey/green & Green & 10 \\
\hline 5CuUZAR-S3/CS:PVA & 5 & 120 & Light blue & Blue & 1.47 \\
\hline 10CuUZAR-S3/CS-PVA & 10 & 114 & Light blue & Blue & 2.93 \\
\hline 15CuUZAR-S3/CS:PVA & 15 & 112 & Light blue & Blue & 4.40 \\
\hline 5CuAM-4/CS:PVA & 5 & 126 & Light blue & Blue & 0.84 \\
\hline 10CuAM-4/CS:PVA & 10 & 123 & Light blue & Blue & 1.68 \\
\hline 15CuAM-4/CS:PVA & 15 & 121 & Light blue & Blue & 2.51 \\
\hline 5CuY/CS:PVA & 5 & 117 & White & Transparent & 0.15 \\
\hline 10CuY/CS:PVA & 10 & 110 & White & Transparent & 0.30 \\
\hline 5CuMOR/CS:PVA & 5 & 116 & White & Transparent & 0.22 \\
\hline 10CuMOR/CS:PVA & 10 & 111 & White & Transparent & 0.45 \\
\hline 5CuBEA/CS:PVA & 5 & 120 & White & Transparent & 0.47 \\
\hline 10CuBEA/CS:PVA & 10 & 114 & White & Transparent & 0.94 \\
\hline
\end{tabular}

${ }^{1} \mathrm{Cu}$ denote the $\mathrm{Cu}$ NP fillers, CuAM-4, and CuUZAR-S3, the Cu-exchanged in layered titanosilicate AM-4 and layered stannosilicate UZAR-S3, respectively, whereas CuY, CuMOR, and CuBEA, denote the Cu-exchanged in zeolites $\mathrm{Y}, \mathrm{MOR}$, and BEA, as described in the Materials section.

This may be caused by the different oxidation states of $\mathrm{Cu}$ depending on its loading and interaction with the polymers and solvents. A blue color is typical of $\mathrm{Cu}(\mathrm{II})$, which can be produced due to the oxidation of metallic copper with water and oxygen as reported by De Godoi et al. [15] according to the following reactions,

$$
\begin{gathered}
2 \mathrm{Cu}_{(\mathrm{s})}^{0}+\mathrm{O}_{2(\mathrm{~g})}+2 \mathrm{H}_{2} \mathrm{O} \rightarrow 2 \mathrm{Cu}_{(\mathrm{aq})}^{+2}+4 \mathrm{OH}_{(\mathrm{aq})}^{-}, \\
\mathrm{Cu}_{(\mathrm{s})}^{0}+2 \mathrm{H}_{2} \mathrm{O} \rightarrow \mathrm{Cu}_{(\mathrm{aq})}^{+2}+\mathrm{H}_{2(\mathrm{~g})}+2 \mathrm{OH}_{(\mathrm{aq})}^{-}
\end{gathered}
$$

On the other hand, the color of the membranes with layered silicates and zeolites could also indicate the $\mathrm{Cu}$ content and oxidation state. When $\mathrm{Cu}$ was ion-exchanged in AM-4 and UZAR-S3, the color of the resulting derived powder and the membranes was blue, while those exchanged in the Y, MOR, and BEA zeolites did not reveal any coloration. This agreed with the real copper content determined by atomic absorption spectrometry, and also shown in the last column of Table 1 . In general, the $\mathrm{Cu}$ content of these membranes agreed with the filler loading, except for the CuAM-4-based membranes, which showed very high $\mathrm{Cu}$ contents due to the higher adsorption capacity as reported elsewhere [20]. This high $\mathrm{Cu}$ cation exchange capacity also produced a slight shift of the X-ray diffraction pattern of CuAM-4 compared to the simulated AM-4 obtained from crystallographic data [33], as represented in Figure 1a.

The X-ray diffractograms in Figure 1 showed the interaction between the layered silicates and the CS:PVA polymer blend at 5 and $10 \mathrm{wt} \%$ values of filler loading. As previously observed, the broad bands of CS and PVA at 10 and $20^{\circ}$ were discerned in the CS:PVA blend membrane and diffuminated upon increasing the layered silicate loading, which could then be attributed to the filler dispersion in the membrane matrix and partial separation of the inorganic layers [32]. 


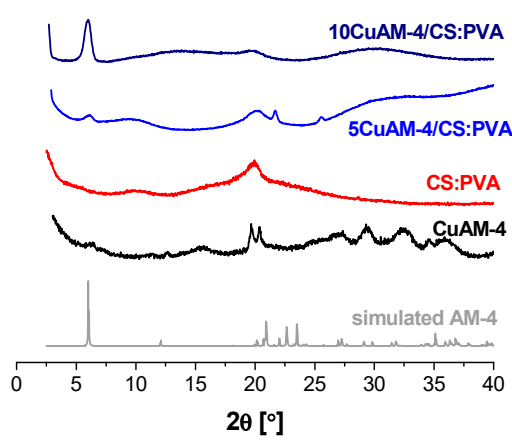

(a)

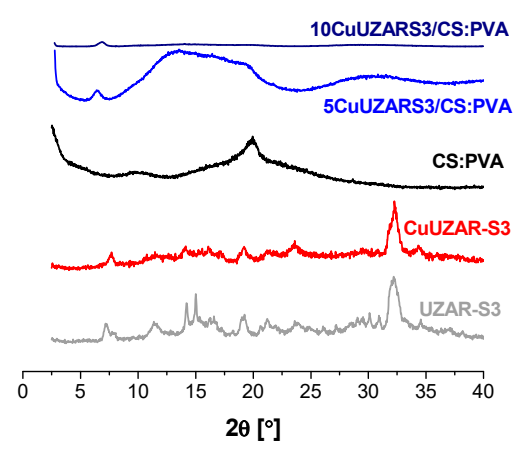

(b)

Figure 1. XRD diffractograms of layered CuAM-4 titanosilicate-filled (a) and CuUZAR-S3 stannosilicate filled (b) CS:PVA mixed matrix membranes.

XPS has been often reported to determine the oxidation state of the $\mathrm{Cu}$ cations after sorption in CS:PVA membranes considering that CS can reduce the metal cations [34]. Thus, to have first insight on the interaction of copper with the CS:PVA polymeric matrix. XPS analyses were conducted on the membrane prepared with the unsupported $\mathrm{Cu}$ NPs and is represented in Figure 2. Cu (II) in CS:PVA blend nanocomposites seemed to be present in the form of 5 different species, $\mathrm{Cu}^{2+}, \mathrm{Cu}(\mathrm{OH})^{+}$, $\mathrm{Cu}(\mathrm{OH})_{2}, \mathrm{Cu}(\mathrm{OH})^{3+}$, and $\mathrm{Cu}(\mathrm{OH})_{4}{ }^{2-}$ as a function of increasing $\mathrm{pH}$ [35]. The summary of the XPS assignments were given in Table $\mathrm{S} 1$ in the Supporting Information section.

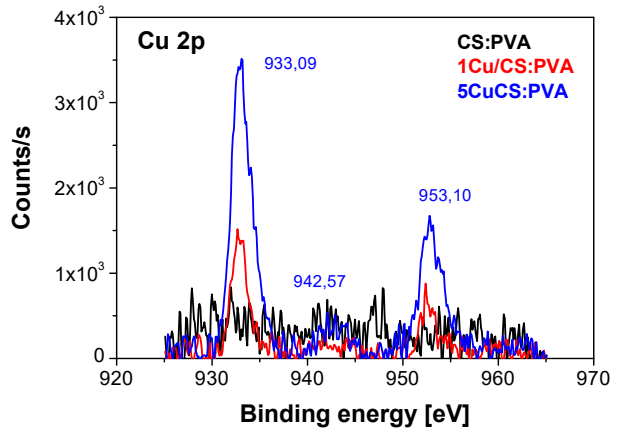

(a)

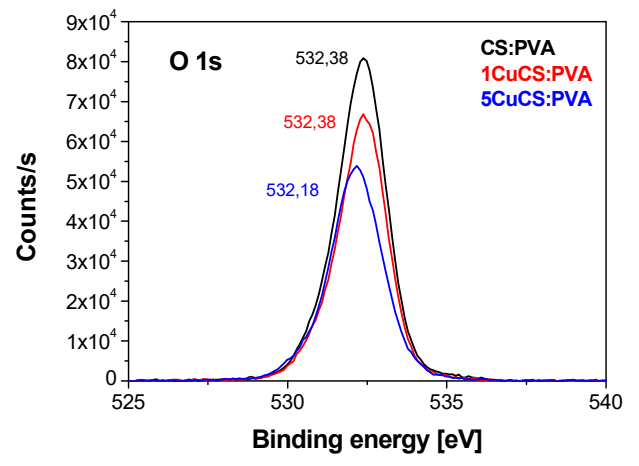

(c)

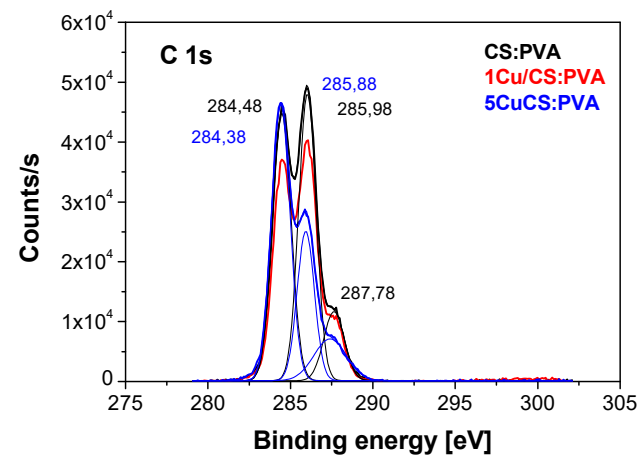

(b)

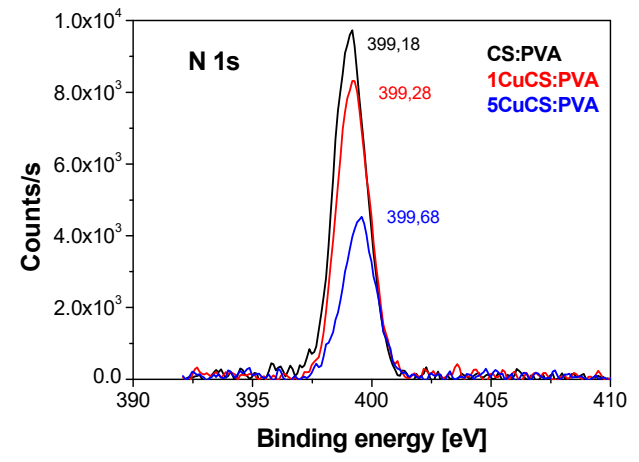

(d)

Figure 2. XPS spectra of Cu 2p (a); C 1s (b); O 1s (c) and N 1s (d) for the Cu/CS:PVA membranes.

Further insight into the $\mathrm{Cu}$ dispersion into the CS:PVA matrix of selected membrane materials was provided by TEM. The TEM image in Figure 3a revealed a homogeneous dispersion of the CuNPs in the CS:PVA matrix, being the size of the NPs $33.5 \pm 0.7-15.8 \pm 1.4 \mathrm{~nm}$. The rings in the electron diffraction pattern of the polycrystalline metal NPs in Figure $3 \mathrm{~b}$ could then be indexed as (0 20$)$ and 
(1 3 1) of $\mathrm{CuO}$ and $\mathrm{Cu}(\mathrm{OH})_{2}$, respectively. This agreed with the literature on $\mathrm{Cu}$ oxidation states, where the $\mathrm{Cu}$ was transformed to $\mathrm{Cu}(\mathrm{OH})_{2}$ upon ion exchange in $1 \mathrm{M} \mathrm{NaOH}$, providing the blue color and further transformations to anion intermediate blue-green species. The change from blue to green color was caused by the reduction of $\mathrm{Cu}$ (II) to $\mathrm{Cu}(\mathrm{I})$, and the formation of $\mathrm{Cu}_{2} \mathrm{O}$ (green) and $\mathrm{CuO}$ (black-brown) species [35]. These patterns were similar to those observed by Domenech et al. for Nafion 117 membranes modified with Ag NPs [36], in the stabilization of CuO by PVP [37] and in the CS-capped copper oxide nanopaint preparation [14].

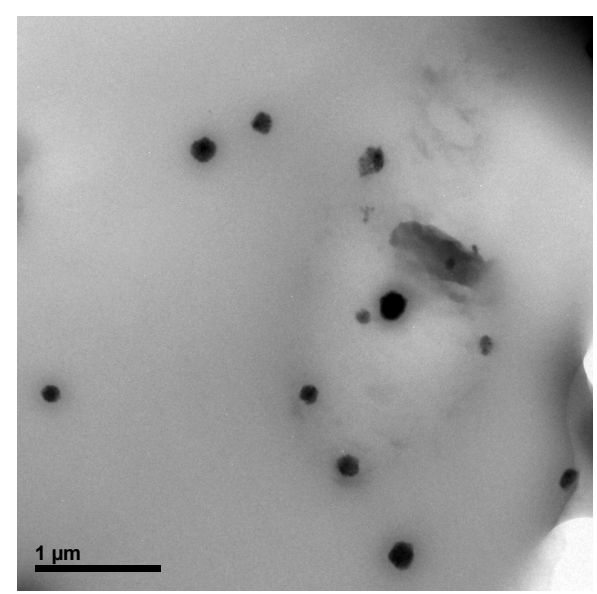

(a)

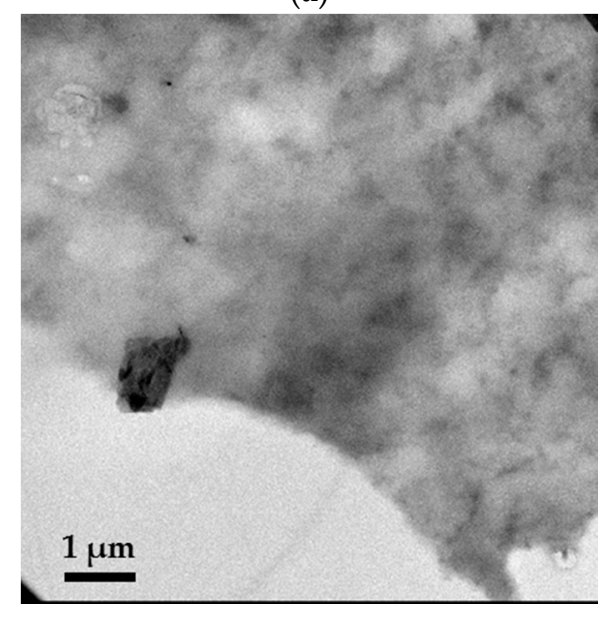

(c)

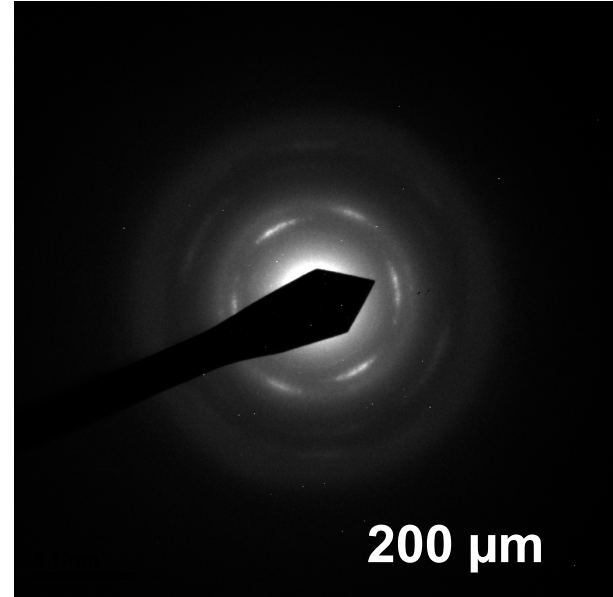

(b)

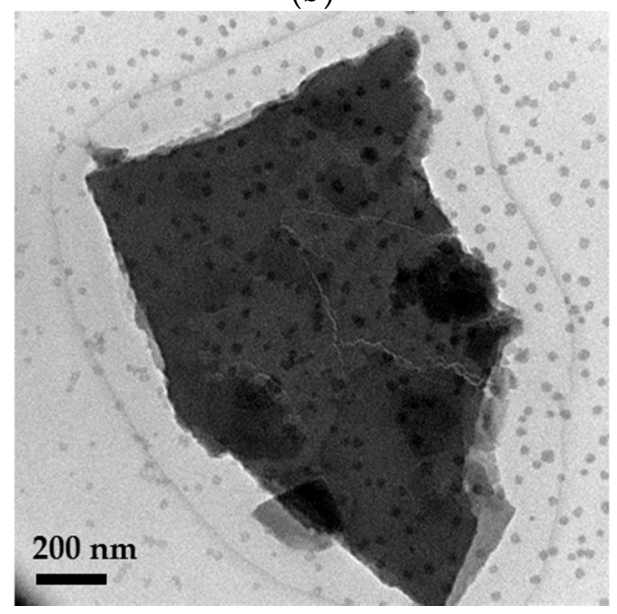

(d)

Figure 3. TEM images of MMM 5Cu/CS-PVA (a) and the electron diffraction to a single Cu NP (b); TEM images of 5CuAM-4/CS:PVA membrane (c) and a detail of 5CuUZAR-S3/CS:PVA membrane (d).

The TEM image of the CS:PVA membranes with a $5 \mathrm{wt} \% \mathrm{Cu}$ exchanged in layered titanosilicate AM-4 presented in Figure 3c revealed the abundant dispersion of the filler in the polymer blend. A detail of a single layered UZAR-S3 particle in a $5 \mathrm{wt} \%$ CuUZAR-S3/CS:PVA membrane was shown at higher magnification in Figure 3d, where the lamella was surrounded by $\mathrm{Cu}$ NPs in a similar way as in the titanosilicate filler [20]. This proved the interest of supporting the copper in a porous inorganic filler that could ease the fabrication of a homogeneously dispersed metal within the polymeric matrix.

In order to obtain a more specific analysis and ensure the bulk chemical composition of Cu-containing CS:PVA membranes, which is not the case for XPS, X-ray absorption synchrotron measurements [31] were carried out, and the normalized energy spectra of the samples were compared with the standard spectra of pure standards, namely, metallic copper foil $(\mathrm{Cu}(0))$, and inorganic oxides $\mathrm{Cu}_{2} \mathrm{O}(\mathrm{Cu}(\mathrm{I}))$ and $\mathrm{CuO}(\mathrm{Cu}(\mathrm{II}))$ oxides, as represented in Figure 4. The edge positions, defined as 
the maximum point of the first derivative function in the rapidly rising edge step of the absorbance vs. energy plot, have been found to be 8979.0, 8980.6, and $8983.6 \mathrm{eV}$ for $\mathrm{Cu}$ foil, $\mathrm{Cu}_{2} \mathrm{O}$, and $\mathrm{CuO}$, respectively [38]. By direct observation of Figure 4a, we could estimate that $\mathrm{Cu}$ in unsupported $\mathrm{CuNPs} / \mathrm{CS}$ :PVA membranes looked evolving from a majority of $\mathrm{Cu}(\mathrm{II})(10 \mathrm{Cu})$ towards $\mathrm{Cu}$ (I) since the rising edge is shifting towards higher energies with increasing filler loading. At higher $\mathrm{Cu}$ content $(10 \mathrm{Cu}$ and $5 \mathrm{Cu})$, a double peak structure of the first derivative of the XANES spectra suggested coexistence of $\mathrm{Cu}^{1+}$ and $\mathrm{Cu}^{2+}$ species. In addition, the global XANES shape evolution in the 8982-8990 eV energy range was directly suggesting the formation of $[\mathrm{CuOH}]^{+}$and $\mathrm{Cu}(\mathrm{OH})_{4}{ }^{2-}$, as a function of increasing $\mathrm{pH}$ [35], as estimated from TEM and XPS analyses above. In the case of the $\mathrm{Cu}$-exchanged layered silicates/CS:PVA membranes (Figure $4 \mathrm{~b}$ ), the XANES spectra were typical of $\mathrm{Cu}(\mathrm{I})$ sites, accounting for their exchange in the porous inorganic structure $[39,40]$ and the favored interaction of copper ions with the amorphous part of CS in the CS:PVA matrix, forming a coordinated bridge between $\mathrm{NH}_{2}$ and $\mathrm{OH}$ [16]. Despite the ongoing challenge for EXAFS and XANES analysis, from XANES spectra in Figure 4 a structural compression could be hypothesized with respect to the reference samples. This agreed with the literature on copper-exchanged zeolites where the feature around $8983 \mathrm{eV}$, corresponding to $\mathrm{Cu}(\mathrm{I})$ species, is not affected, being that the $\mathrm{Cu}$ was not oxidized in the presence of water [40]. Therefore, the results of the XANES/EXAFS spectra agreed with previous observations regarding the stability of the $\mathrm{Cu}$ in the supported inorganic fillers in comparison with the unsupported $\mathrm{Cu}$ NPs in the CS:PVA blend polymer matrix.

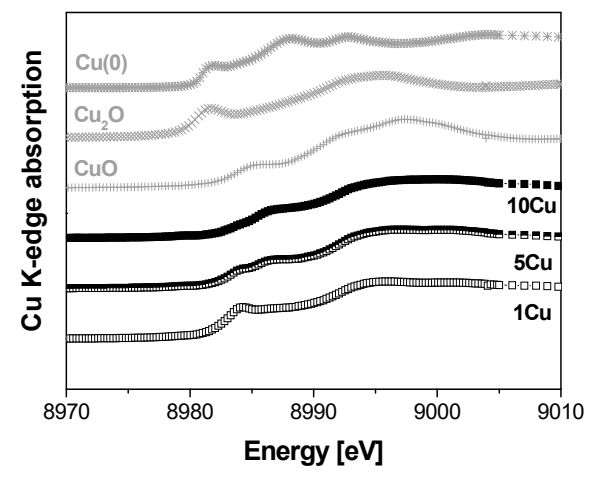

(a)

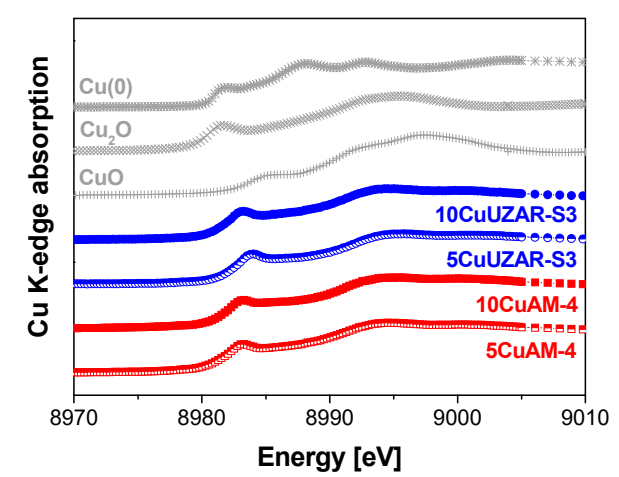

(b)

Figure 4. Normalized Cu K-edge XANES spectra for CS:PVA membrane samples filled with unsupported $\mathrm{Cu}$ NPs (a) and Cu-exchanged layered titanosilicate AM-4 and stannosilicate UZAR-S3 (b). References used for the linear combination $\left(\mathrm{Cu}\right.$ foil, $\mathrm{Cu}_{2} \mathrm{O}$, and $\left.\mathrm{CuO}\right)$ are also shown above.

The WU, IEC, and $\mathrm{OH}^{-}$conductivity of the prepared membranes in $\mathrm{OH}^{-}$form were shown in Table 2. As expected, the addition of $\mathrm{Cu}$ NPs decreased the WU of the CS:PVA membranes, as reported for Ag NPs in Nafion 117 [6]; in CS [14] IEC increased, with $5 \mathrm{wt} \%$ as the apparent optimum Cu NPs loading. This was attributed to the different oxidation states of $\mathrm{Cu}$ we shown above. As expected, the addition of $\mathrm{Cu}$ NPs decreased the hydrophilicity of the membranes. On the other hand the optimum filler loading for the layered silicate seemed to be $10 \mathrm{wt} \%$, since the IEC of the membranes with $10 \mathrm{wt} \% \mathrm{CuAM}-4$ and CuUZAR-S3 was higher than those reached at $5 \mathrm{wt} \%$ loadings. In fact, the values obtained $(0.464 \mathrm{mmol} / \mathrm{g}$ for the 10CuAM4/CS-PVA membrane and $0.451 \mathrm{mmol} / \mathrm{g}$ for the 10CuUZAR-S3/CS-PVA membrane) were above the value measured for the commercial FAA-3 membrane $(0.364 \mathrm{mmol} / \mathrm{g})$.

WU was reduced by the introduction of the $\mathrm{Cu}$-based fillers, except for the layered silicates whose hydrophilic character was larger than the ones provided by the other type of fillers. This confirmed the hydrophilic character of this kind of filler [41]. In fact, a large amount of water-induced swelling was observed for the $\mathrm{Cu}$ exchanged in layered silicates-filled CS:PVA membranes, in detrition of the mechanical properties of these membranes. The particular case of the membranes with $\mathrm{Cu}$ exchanged 
on AM-4 showed that this kind of filler tended to increase the WU values. The high hydrophilic character of the titanosilicate surpassed the capacity of $\mathrm{Cu}$ to control this property and thus, by increasing the amount of filler, the WU also increased. Then, $\mathrm{Cu}$-exchanged zeolites $\mathrm{Y}, \mathrm{MOR}$, and BEA-filled membranes were also prepared. Although $\mathrm{Cu}$-exchanged zeolites were very difficult to observe under TEM, because of the resistance opposed by the 3D particles to the diamond knife upon sample preparation, and due to the lower homogeneity in their dispersion through the membrane matrix, the XRD diagrams in the zeolite filled membranes corroborated the presence of CuY, CuBEA, and CuMOR in Figure 5a-c, respectively. As expected, the relative intensity of the CS and PVA main peaks diminished upon increasing loading of the crystalline zeolite content [41], despite the presence of some impurities in the sample holder in some samples ( $33^{\circ}$ peak in Figure $\left.5 \mathrm{a}, \mathrm{c}\right)$. They presented lower $\mathrm{WU}$ values than the pristine polymer membrane and the ones retrieved for the membranes filled with CuAM-4 and CuUZAR-S3, especially those filled by CuMOR, regardless the filler loading. The IEC of Cu-exchanged zeolite filled CS:PVA MMMs also showed similar values at 5 and $10 \mathrm{wt} \%$ filler loadings, even surpassing the IEC value of the FAA-3 membrane in the case of 5CuMOR/CS:PVA membrane. These observations led to the conclusion that it may be the type of filler and not the $\mathrm{Cu}$ content that was influencing the physicochemical properties of the membranes.

Table 2. WU, IEC, and $\mathrm{OH}^{-}$conductivity, and WVP and thickness of the membranes studied in this work.

\begin{tabular}{|c|c|c|c|c|c|}
\hline Membrane & $\begin{array}{c}\text { WU } \\
(\text { wt \%) }\end{array}$ & $\begin{array}{c}\text { IEC } \\
(\mathrm{mmol} / \mathrm{g})\end{array}$ & $\begin{array}{l}\text { Conductivity } \\
(\mathrm{mS} / \mathrm{cm})\end{array}$ & $\begin{array}{c}\text { WVP } \\
\left(\mathrm{g} \cdot \mathrm{mm} / \mathrm{m}^{2} \cdot \mathrm{h} \cdot \mathrm{kPa}\right)\end{array}$ & $\begin{array}{c}\text { Thickness } \\
(\mu \mathrm{m})\end{array}$ \\
\hline FAA-3 & $23.2 \pm 2.9$ & $0.36 \pm 0.021$ & $2.92[28]$ & 1.159 & $41 \pm 1^{2}$ \\
\hline CS:PVA & $60.1 \pm 2.9$ & $0.27 \pm 0.03$ & $0.26 \pm 0.06$ & $0.577 \pm 0.043$ & $38 \pm 4$ \\
\hline 5Cu/CS:PVA & $47.2 \pm 2.8$ & $0.37 \pm 0.12$ & -1 & $2.187 \pm 0.073$ & $183 \pm 27$ \\
\hline 10Cu/CS:PVA & $51.4 \pm 4.3$ & $0.28 \pm 0.04$ & 0.218 & $1.354 \pm 0.117$ & $130 \pm 32$ \\
\hline 5CuUZAR-S3/CS:PVA & $56.5 \pm 3.3$ & $0.27 \pm 0.01$ & $0.28 \pm 0.00$ & $1.632 \pm 0.590$ & $74 \pm 7$ \\
\hline 10CuUZAR-S3/CS:PVA & $59.5 \pm 1.3$ & $0.45 \pm 0.05$ & $0.71 \pm 0.10$ & $0.427 \pm 0.100$ & $83 \pm 12$ \\
\hline 15CuUZAR-S3/CS:PVA & $75.4 \pm 2.2$ & $0.448 \pm 0.01$ & $0.20 \pm 0.05$ & $0.375 \pm 0.062$ & $57 \pm 5$ \\
\hline 5CuAM-4/CS:PVA & $60.8 \pm 1.7$ & $0.22 \pm 0.02$ & $0.25 \pm 0.14$ & $0.466 \pm 0.049$ & $71 \pm 9$ \\
\hline 10CuAM4/CS:PVA & $64.7 \pm 1.2$ & $0.46 \pm 0.07$ & $0.90 \pm 0.36$ & $0.348 \pm 0.042$ & $91 \pm 11$ \\
\hline 15CuAM-4/CS:PVA & $71.2 \pm 2.3$ & $0.44 \pm 0.01$ & $0.46 \pm 0.13$ & $0.330 \pm 0.104$ & $62 \pm 7$ \\
\hline 5CuY/CS:PVA & $56.8 \pm 0.7$ & $0.30 \pm 0.03$ & $0.32 \pm 0.02$ & $0.333 \pm 0.042$ & $77 \pm 3$ \\
\hline 10CuY/CS:PVA & $56.3 \pm 0.9$ & $0.29 \pm 0.02$ & $0.34 \pm 0.08$ & $0.290 \pm 0.139$ & $52 \pm 8$ \\
\hline 5CuMOR/CS:PVA & $49.8 \pm 5.6$ & $0.37 \pm 0.02$ & $0.18 \pm 0.01$ & $0.390 \pm 0.147$ & $64 \pm 9$ \\
\hline 10CuMOR/CS:PVA & $48.0 \pm 4.4$ & $0.34 \pm 0.05$ & $0.51 \pm 0.16$ & $0.336 \pm 0.047$ & $64 \pm 6$ \\
\hline 5CuBEA/CS:PVA & $59.8 \pm 0.8$ & $0.24 \pm 0.02$ & -1 & $0.219 \pm 0.012$ & $46 \pm 10$ \\
\hline 10CuBEA/CS:PVA & $58.3 \pm 5.6$ & $0.21 \pm 0.02$ & $0.33 \pm 0.07$ & $0.287 \pm 0.042$ & $53 \pm 2$ \\
\hline
\end{tabular}

Likewise, the $\mathrm{OH}^{-}$conductivity followed a trend similar to that of the IEC. As conductivity depended on both IEC and WU, it was therefore influenced by the type of filler. Maximum conductivity values were reached at $10 \mathrm{wt} \%$ loading for the $\mathrm{Cu}$ ion-exchanged layered AM-4 and UZAR-S3, although CuMOR also showed a relevant improvement. The highest $\mathrm{OH}^{-}$conductivity was obtained for the membranes where $\mathrm{Cu}$ was ion-exchanged in the layered UZAR-S3 and AM-4 and the zeolites $\mathrm{Y}$ and MOR, as shown in Table 2, although still far from the commercial FAA-3 membrane measured in the same way. This comparison with the commercial membranes in the same measurement conditions, as well as checking the whole membrane region by measuring at different pieces of each membrane sample, have proved the reliability of our measurement in alkaline conditions, although it is true that anion-exchange membranes in $\mathrm{OH}^{-}$form exposed to ambient air in humid conditions may undergo the partial transformation of $\mathrm{OH}^{-}$to bicarbonate and carbonate anions that would mask the measurement of $\mathrm{OH}^{-}$conductivity [26]. The stability of CS:PVA based membranes in alkaline media has been corroborated previously when similar efficiencies to the commercial Fumatech membrane 
were obtained, though [42]. Details on the $\mathrm{Cu}$ state in the membrane framework could be observed in the FT-EXAFS spectra in Figure S2 (Supporting Information).

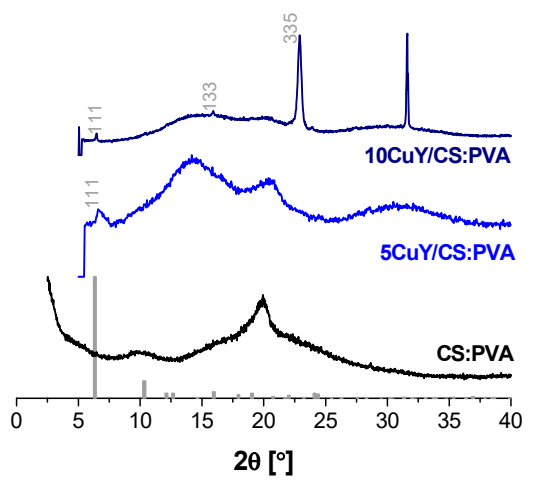

(a)

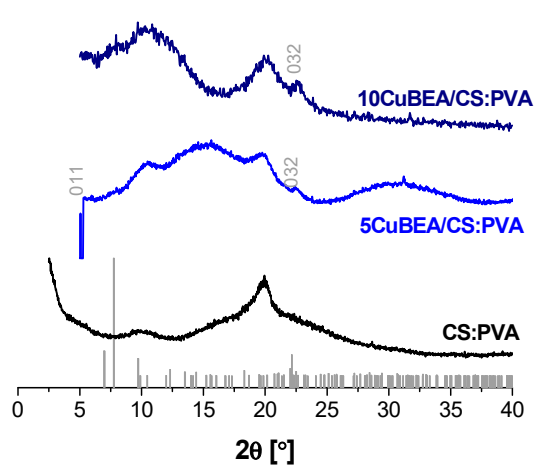

(b)

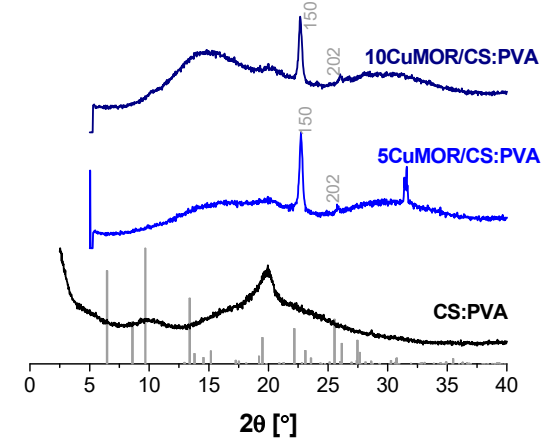

(c)

Figure 5. XRD diffractograms of CuY (a); CuBEA (b); and CuMOR (c) filled CS:PVA MMMs. The simulated patterns were taken from the crystallographic data of the International Zeolite Database (www.iza-structure.org/databases/).

The relationship between IEC and WU for all the membranes prepared with the layered fillers, CuAM-4 and CuUZAR-S3, showed a linear dependence with adjustable $R^{2}$ larger than $89 \%$ and a significant adjustment $(p<0.05)$. That was the reason for producing the membranes with $15 \mathrm{wt} \%$ filler loading in these cases, at this point. However, a filler loading of $15 \mathrm{wt} \%$ did not improve the IEC or the $\mathrm{OH}^{-}$conductivity any further. Thus, the general optimum value of inorganic filler loading seemed to be $10 \mathrm{wt} \%$. A higher amount of inorganic particles in the polymeric matrix probably hindered the mobility of anions and water molecules through the membrane, without altering the oxidation state of $\mathrm{Cu}$ in the membrane [43].

In addition, by looking at Figure $4 \mathrm{~b}$, we observed that when the $\mathrm{Cu}$ oxidation state looked lower (main feature at lower energy), the conductivity and IEC in Table 2 were higher. This revealed a correlation between the $\mathrm{Cu}$ oxidation state and the electrochemical functional properties.

The correct correlation between water content and water vapor permeability (WVP) may establish new AEM designs for electrochemical applications [3], taking into account that an excessive WU can also lead to dilution of the groups allowing the water and ions transport and, consequently, a reduction of the anion conductivity [44]. As a consequence, there is a trade-off between these membrane properties, which is the reason why it was interesting that the anion conductivity of the 10CuAM-4/CS:PVA membrane increased without a great change in the WU, although the conductivity of the FAA-3 commercial membrane was not surpassed. As shown in Table 2, the WVP varied with the inclusion of the $\mathrm{Cu}$-exchanged particles and the water sorption capacity of the inorganic filler. Every type of filler support for $\mathrm{Cu}$ used in this work, except for the unsupported CuNPs and CuBEA, acted as a water barrier through the polymeric matrix, reducing the permeability compared to the 
membrane without the inorganic filler added. The values obtained were in the same of order of magnitude as other equimolar CS-alginate blends reported in the literature [45]. Those fillers of superior hydrophilic character, like $\mathrm{CuY}$ and CuMOR, showed a significant $(p<0.05)$ relationship between WVP and WU, with a negative relationship, which meant that the WVP decreased with decreasing WU in the membrane. This was due to the water retention in the interstitial spaces between the polymer chains and the inorganic fillers [46]. This phenomenon did not occur for CuNPs or CuBEA-filled CS:PVA membranes, which could explain why WVP increased when adding these highly hydrophobic fillers.

The thermogravimetric curves of the CS-PVA-based MMMs in air and nitrogen are displayed in Figure $6 a, b$, respectively. The shape of the curves was very similar to previously reported TGAs for CS:PVA blends [10], no matter what type of filler was used. The same characteristic weight losses for CS and PVA in the CS:PVA blend membranes were observed, as reported in a previous work [10]. The first weight loss at $119^{\circ} \mathrm{C}$ represented the free water content, which is the difference between the excess of water after rinsing and immersing the membrane for the measurement of the WU and the bound water determined by the hydrophilic character of the polymer [47]. The second weight loss corresponded to the polymer chain degradation and varies between 246 and $334{ }^{\circ} \mathrm{C}$ for all the membranes. The weight loss at $119^{\circ} \mathrm{C}$ and at the thermal decomposition, $\mathrm{T}_{2}$, calculated from the TGA curves in $\mathrm{N}_{2}$ in Figure $6 \mathrm{~b}$ were given in Table S2. These values were close to the thermal decomposition temperature of CS membranes $\left(329.5^{\circ} \mathrm{C}\right)$ having a weight loss of $8.95 \mathrm{wt} \%$ [45]. The decomposition temperature varied, but it is near $200{ }^{\circ} \mathrm{C}$ for every membrane. The different peaks through this phase of decomposition could be attributed to the degradation influence of the different types of fillers on the degradation of the polymer matrix. The average residual weight values of the membranes were $5 \pm 0.35,5.31 \pm 0.47$, $10.54 \pm 0.05,4.7 \pm 0.06,6.04 \pm 0.4$, and $7.21 \pm 0.28 \mathrm{wt} \%$ for the $\mathrm{Cu} / \mathrm{CS}:$ PVA, CuUZAR-S3/CS:PVA, CuAM-4/CS:PVA, and CuY/CS:PVA membranes, respectively, which, comparing with the nominal weight of the inorganic fillers $(5,10,15 \mathrm{wt} \%)$, could signify a rather heterogeneous distribution of the particles throughout the membrane matrix. This heterogeneous distribution was clearly observed with the naked eye for CuBEA and CuMOR filled CS:PVA membranes, which probably explained the differences in the TGA curves in Figure 6 compared with the values displayed by the other membranes.

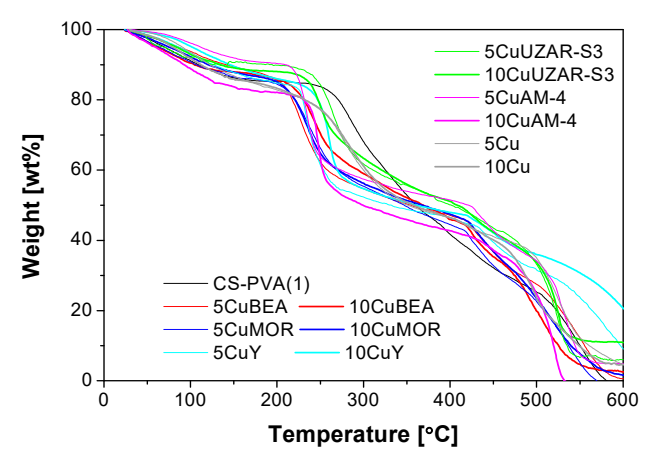

(a)

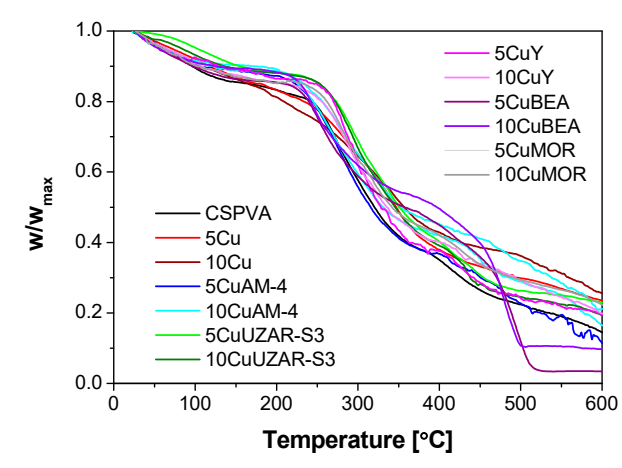

(b)

Figure 6. Thermal decomposition of the CS:PVA-based membranes under air (a) and nitrogen (b).

For stability analysis, the WC, the bound water content of the AEMs was calculated by Equation (6), following the method of Franck-Lackaze et al. [28] (Table S2). Although the WC of the pristine CS:PVA membrane agreed with that obtained previously [10], the WC of layered CuAM-4/CS:PVA and CuUZAR-S3/CS:PVA membranes was higher than the values obtained previously for the unexchanged AM-4 and UZAR-S3/CS:PVA membranes [10]. This could be attributed to the success of the $\mathrm{Cu}$-exchange in the silicate layer structure prior to the preparation of the membranes. The WC increased upon addition of CuAM-4, CuUZAR-S3, and CuY, and decreased when adding Cu NPs up to $5 \mathrm{wt} \%$, CuMOR and CuBEA, as an indicator of the higher hydrophobic character of the latter 
type of fillers, compared to the formerly mentioned ones. As a conclusion, the thermal decomposition temperature decreased with the hydrophilic filler loading, and increased slightly with the hydrophobic filler content.

\subsection{Mechanical Properties}

The Cu-exchange has been reported to decrease the tensile strength (TS) of Neosepta membranes from $2.67 \pm 0.75 \mathrm{~kg} / \mathrm{m}^{2}$ to $2.26 \pm 0.39 \mathrm{~kg} / \mathrm{m}^{2}$ [48]. Metal nanoparticles have not been observed to improve the TS performance of hydrophilic Nafion membranes either [6]. The results of 2-7 repetitions of the TS experiments performed for every CS:PVA membrane sample in this work are collected in Table 3. The TS of uncross-linked CS has been reported as $1.38 \mathrm{~N} / \mathrm{mm}^{2}$, in the order of magnitude of the TS values observed in this work (Table 3) although the values for organically cross-linked CS:PVA membranes under dry conditions given in the literature were around $65.53 \pm 6.9 \mathrm{~N} / \mathrm{mm}^{2}$, with an elongation at break of $11.05 \% \pm 1.3 \%$ [11,12,49]. The overall trend of TS of the membranes in this work was lower than those previously obtained, those were obtained on cross-linked membranes using glutaraldehyde and trimesoyl chloride, which also reduced WU and anion exchange capacity [50], in contrast with our membranes.

Table 3. Tensile strength and elongation at break of the wet Cu-filled CS:PVA membranes.

\begin{tabular}{|c|c|c|}
\hline Membrane & $\mathrm{TS}\left(\mathrm{N} / \mathrm{mm}^{2}\right)$ & e $(\%)$ \\
\hline 5Cu/CS:PVA & 0.14 & 1.71 \\
\hline 10Cu/CS:PVA & 0.11 & 1.49 \\
\hline 5CuUZAR-S3/CS:PVA & $4.34 \pm 2.07$ & $56 \pm 13$ \\
\hline 10CuUZAR-S3/CS:PVA & $1.18 \pm 0.23$ & $57 \pm 40$ \\
\hline 15CuUZAR-S3/CS:PVA & $0.94 \pm 0.09$ & $55 \pm 9.5$ \\
\hline 5CuAM-4/CS:PVA & $2.14 \pm 0.10$ & $66 \pm 0.9$ \\
\hline 10CuAM-4/CS:PVA & $0.34 \pm 0.05$ & $79 \pm 7.0$ \\
\hline 15CuAM-4/CS:PVA & $0.24 \pm 0.11$ & $18 \pm 15$ \\
\hline 5CuY/CS:PVA & $3.51 \pm 2.48$ & $44 \pm 3.1$ \\
\hline 10CuY/CS:PVA & $7.57 \pm 4.10$ & $36 \pm 8.9$ \\
\hline 5CuMOR/CS:PVA & $0.36 \pm 0.03$ & $30 \pm 12$ \\
\hline 10CuMOR/CS:PVA & $4.83 \pm 1.62$ & $37 \pm 11$ \\
\hline 5Cu-BEA/CS:PVA & $0.72 \pm 0.25$ & $56 \pm 5.9$ \\
\hline 10Cu-BEA/CS:PVA & $0.64 \pm 0.24$ & $67 \pm 20$ \\
\hline
\end{tabular}

Nevertheless, the metal supported in layered AM-4 and UZAR-S3, as well as in zeolites $\mathrm{Y}$ and MOR, showed a slight improvement in the TS under wet conditions, compared to the pure CS:PVA blend polymer membrane. However, the membranes filled by unsupported $\mathrm{Cu}$, as well as high loading UZAR-S3, experienced high degree of swelling.

The mechanical properties could thus be related to the ion exchange capacities shown in Table 2, since the higher the IEC, the lower the TS values, as reported for other AEMs [24].

\subsection{ANOVA-Based Statistical Analysis}

A statistical analysis of all the measured properties (WU, IEC, conductivity, WVP, thickness, TS, and elongation at break) was carried out to confirm the observations presented in the previous sections. The ANOVA analysis was performed to determine which factors (type of filler, filler loading, or $\mathrm{Cu}$ content) and how, have a statistically significant effect on each parameter. These variables were selected because already Kikhavani et al. [51] observed that the ratio filler/polymer had an effect on the accessibility to the surface of inorganic particles used as fillers that affected the IEC and conductivity of AAEMs. The polymer blend ratio or the solvent used had been observed to have an effect in water sorption (WU) [11]. The effect of the type of filler was evaluated qualitatively.

The results of the ANOVA analyses for the different parameters with significance $(p<0.05)$ in all or some of the factor contributions are shown in Tables $4-7$, while the rest can be found in 
Tables S3-S5 of the Supporting Information. The ANOVA in Table 4 indicated that while the thickness of the membranes depended significantly on all the three input factors (type of filler, filler loading, and copper content), according to results in Table 5, WU varied as a function of the type of filler and $\mathrm{Cu}$ content, with a lesser dependence in filler loading, which agreed with the observations discussed earlier in this work, while the elongation at the break in Table 7 only depended on the type of filler and filler loading. Contrarily, the tensile strength in Table 6 depended mainly on the filler loading, regardless the copper content and the type of filler support.

Table 4. ANOVA for parameter thickness (mm).

\begin{tabular}{cccccc}
\hline Source & Sum of Squares (SS) & Degree of Freedom (df) & Mean Square (MS) & $F$-Value & $p$-Value \\
\hline Main effects & & & & & \\
A-Type of filler & $9.73 \times 10^{-3}$ & 5 & $1.94 \times 10^{-3}$ & 57.24 & 0.017 \\
B-Filler loading & $2.84 \times 10^{-3}$ & 1 & $2.84 \times 10^{-3}$ & 83.46 & 0.012 \\
C-Cu content & $8.52 \times 10^{-4}$ & 1 & & & \\
\hline Interaction & & & $1.65 \times 10^{-4}$ & 25.07 & 0.038 \\
A $\times$ B & $8.27 \times 10^{-3}$ & 5 & $1.89 \times 10^{-3}$ & 48.62 & 0.020 \\
B $\times$ C & $1.89 \times 10^{-3}$ & 1 & $2.06 \times 10^{-4}$ & 65.65 & 0.018 \\
A $\times$ B $\times$ C & $8.26 \times 10^{-4}$ & 4 & $3.4 \times 10^{-5}$ & & 0.146 \\
Residual & $6.8 \times 10^{-5}$ & 2 & & & \\
\hline Total & 0.024 & 19 & & & \\
\hline
\end{tabular}

Table 5. ANOVA for parameter WU (wt \%).

\begin{tabular}{|c|c|c|c|c|c|}
\hline Source & Sum of Squares (SS) & Degree of Freedom (df) & Mean Square (MS) & $F$-Value & $p$-Value \\
\hline \multicolumn{6}{|l|}{ Main effects } \\
\hline A-Type of filler & 405 & 5 & 81 & 80.16 & 0.012 \\
\hline B-Filler loading & 14.8 & 1 & 14.77 & 10.62 & 0.062 \\
\hline $\mathrm{C}-\mathrm{Cu}$ content & 246 & 1 & 245.9 & 243.4 & 0.004 \\
\hline \multicolumn{6}{|l|}{ Interaction } \\
\hline $\mathrm{A} \times \mathrm{B}$ & 96.4 & 5 & 19.28 & 19.08 & 0.050 \\
\hline $\mathrm{B} \times \mathrm{C}$ & 100.4 & 1 & 100.4 & 99.39 & 0.010 \\
\hline $\mathrm{A} \times \mathrm{B} \times \mathrm{C}$ & 16.9 & 4 & 4.23 & 4.186 & 0.202 \\
\hline Residual & 2.0 & 2 & 1.01 & & \\
\hline Total & 881.5 & 19 & & & \\
\hline
\end{tabular}

Table 6. ANOVA for parameter TS $\left(\mathrm{N} / \mathrm{mm}^{2}\right)$.

\begin{tabular}{|c|c|c|c|c|c|}
\hline Source & Sum of Squares (SS) & Degree of Freedom (df) & Mean Square (MS) & $F$-Value & $p$-Value \\
\hline \multicolumn{6}{|l|}{ Main effects } \\
\hline A-Type of filler & 184 & 5 & 37 & 0.231 & 0.919 \\
\hline B-Filler loading & 110,811 & 1 & 11,081 & 69.55 & 0.014 \\
\hline $\mathrm{C}-\mathrm{Cu}$ content & 571 & 1 & 571 & 3.581 & 0.199 \\
\hline \multicolumn{6}{|l|}{ Interaction } \\
\hline $\mathrm{A} \times \mathrm{B}$ & 733 & 5 & 147 & 0.921 & 0.594 \\
\hline $\mathrm{B} \times \mathrm{C}$ & 2221 & 1 & 2221 & 13.94 & 0.065 \\
\hline $\mathrm{A} \times \mathrm{B} \times \mathrm{C}$ & 1910 & 4 & 477 & 2.997 & 0.266 \\
\hline Residual & 319 & 2 & 159 & & \\
\hline Total & 116,749 & 19 & & & \\
\hline
\end{tabular}


Table 7. ANOVA for parameter elongation at break (\%).

\begin{tabular}{cccccc}
\hline Source & Sum of Squares (SS) & Degree of Freedom (df) & Mean Square (MS) & $\boldsymbol{F}$-Value & $\boldsymbol{p}$-Value \\
\hline Main effects & & & & & \\
A-Type of filler & 3734 & 5 & 746.7 & 15.21 & 0.063 \\
B-Filler loading & 1737 & 1 & 1737 & 35.38 & 0.027 \\
C-Cu content & 1 & 1 & 0.8 & 0.016 & 0.910 \\
\hline Interaction & 1436 & 5 & 287.1 & 5.847 & 0.152 \\
$\mathrm{~A} \times \mathrm{B}$ & 2318 & 1 & 2317 & 47.20 & 0.020 \\
$\mathrm{~B} \times \mathrm{C}$ & 1419 & 4 & 354.8 & 7.224 & 0.125 \\
$\mathrm{~A} \times \mathrm{B} \times \mathrm{C}$ & 98 & 2 & 49.1 & & \\
Residual & 10,743 & 19 & &
\end{tabular}

In this work, a first order linear model with interactions was considered for the parameters WU and thickness. In each case, only the factors and interactions that have a statistically significant effect on the property, as determined above, were included in the regression model. The surface responses thus obtained for each model parameter were plotted qualitatively in the contour plots in Figure 7, for the hydrophilic properties WU and WVP, and the thickness, because of its influence in WVP, as a function of filler loading and copper content.

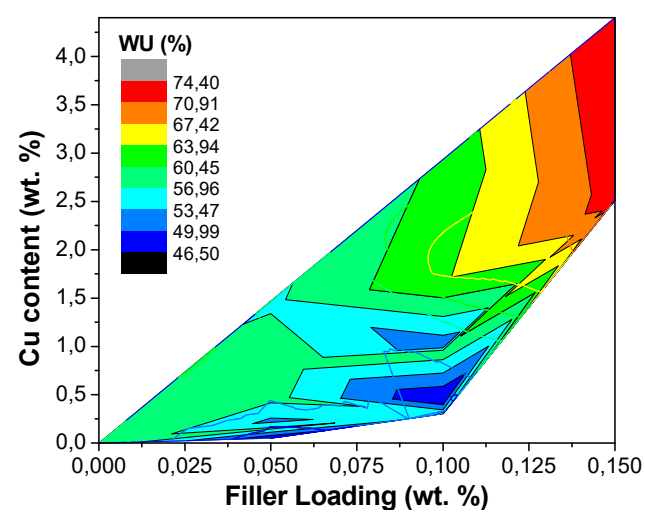

(a)

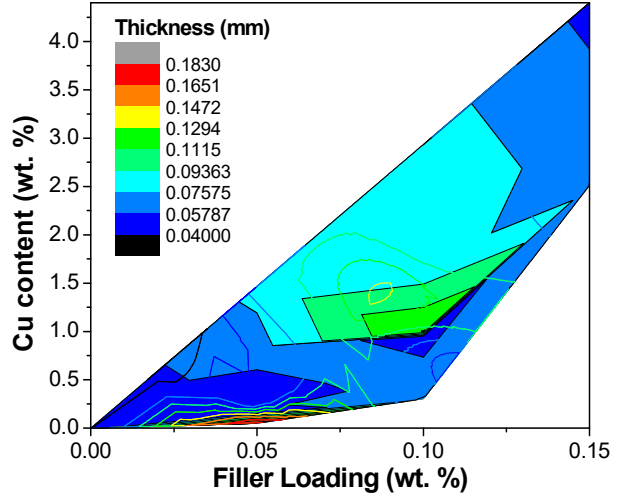

(b)

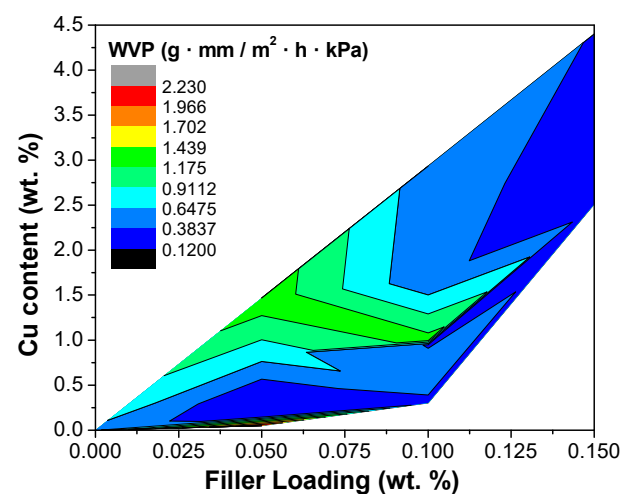

(c)

Figure 7. Contour plots of the regression models obtained for parameters WU (a); thickness (b) and WVP (c).

The hypotheses of independence, statistical significance, normality, and homoscedasticity have to be met in order to confirm the validity of the ANOVA analysis [52]. On the one hand, the homoscedasticity was checked by the studentized Breusch-Pagan test, with a confidence level of $95 \%$. On the other hand, 
the normality hypothesis was verified using the unidimensional statistics of the ANOVA residuals, by the Shapiro-Wilk and Jarque-Bera tests. Nevertheless, these validations were not shown here for the sake of simplicity [53].

Figure 7 confirmed that the WU increased with increasing $\mathrm{Cu}$ content and filler loading in the CS:PVA based membranes (Figure 7a), while the thickness and WVP only increased up to a maximum as observed in the previous section, in agreement with the literature [53]. In addition, it was observed that the influence of the factors filler loading and $\mathrm{Cu}$ content with a statistically significant secondary effect on the other properties (IEC, conductivity, TS, and elongation) like WVP with the thickness, could be estimated from, by considering the contribution of the primary factors on the thickness and WU. These qualitative model fitting data are reported in the Supporting information section.

\section{Conclusions}

In this study, the preparation of AAEMs from renewable and low-cost polymers has been optimized, as a function of the type of inorganic filler support, filler loading, and $\mathrm{Cu}$ content, regarding different properties (IEC, WU, WVP, thickness, TS, elongation at break, and conductivity). The copper content was introduced in the polymer CS:PVA blend matrix either as unsupported commercial nanoparticles, or ion-exchanged in various porous supports like AM-4, layered UZAR-S3 stannosilicate, and zeolites Y, MOR, and BEA. The WU, IEC, and anion conductivity can be controlled by the addition of the metal particles, by altering the hydrophilicity and ion and water sorption and permeability of the hydrophilic polymer blend. In contrast, chemical, thermal, and mechanical resistance are better controlled when the metal is exchanged in a porous inorganic matrix. Moreover, fillers of hydrophilic nature, i.e., CuAM-4, CuUZAR-S3, and CuMOR, showed the best results in ion exchange and conductivity.

In order to find the optimum conditions as a compromise between the electrochemical and water management properties, a three variable factors ANOVA was conducted to identify the optimum values of the three factors. The optimum filler loading seemed to be $10 \mathrm{wt} \%$. The predicted values for WU, WVP, and thickness were confirmed experimentally with high precision. The results from this analysis give scope for a further optimization and development of novel anion-exchange hydrophilic membranes for electrochemical applications, or even as antifouling membrane coatings in water treatment, although a significant amount of work is still to be carried out regarding the evaluation of carbonation and influence of different anion species in the polyelectrolyte membrane performance.

Supplementary Materials: The following are available online at http:/ / www.mdpi.com/2073-4360/10/8/913/ s1.

Author Contributions: The conceptualization, data collection, and analysis was carried out by A.M.-M., who also wrote the initial draft; the supervision, calculation, methodology, and writing of the manuscript was realized by C.C.-C.; L.G.-C. and J.I. carried out the electrochemical measurements and analysis of anionic impedances; M.d.M.E.-B., V.S., and M.A. were in charge of the mechanical analyses and TEM observations; L.S. contributed her expertise in the analysis of the observations obtained at synchrotron. Á.I. contributed fruitful deep discussions on the statistical analyses of the results, his large expertise to focus the results of the work into the global perspective, and last but not least, procured the funding. All authors revised the several versions of the manuscript before submission and upon revision.

Funding: This research was funded by Spanish Ministry of Science, Innovation, and Universities under project number CTQ2016-76231-C2-1-R at the Universidad de Cantabria.

Acknowledgments: The XANES experiments were carried out at the CLAESS beamline at ALBA Synchrotron with the collaboration of beamline staff and CALIPSOplus (Grant 730872) funding, for which they are gratefully acknowledged.

Conflicts of Interest: The authors declare no conflicts of interest.

\section{References}

1. Varcoe, J.R.; Atanassov, P.; Dekel, D.R.; Herring, A.M.; Hickner, M.A.; Kohl, P.A.; Kucernak, A.R.; Mustain, W.E.; Nijmeijer, K.; Scott, K.; et al. Anion-exchange membranes in electrochemical energy systems. Energy Environ. Sci. 2014, 7, 3135-3191. [CrossRef] 
2. Dekel, D.R. Review of cell performance in anion exchange membrane fuel cells. J. Power Sources 2018, 375, 158-169. [CrossRef]

3. Gottesfeld, S.; Dekel, D.R.; Page, M.; Bae, C.; Yan, Y.; Zelenay, P.; Kim, Y.S. Anion exchange membrane fuel cells: Current status and remaining challenges. J. Power Sources 2018, 375, 170-184. [CrossRef]

4. Deng, H.; Wang, D.; Xie, X.; Zhou, Y.; Yin, Y.; Du, Q.; Jiao, K. Modeling of hydrogen alkaline membrane fuel cell with interfacial effect and water management optimization. Renew. Energy 2016, 91, 166-177. [CrossRef]

5. Park, C.H.; Lee, S.Y.; Hwang, D.S.; Shin, D.W.; Cho, D.H.; Lee, K.H.; Kim, T.; Hill, A.J.; Guiver, M.D.; Kim, T.; et al. Nanocrack-regulated self-humidifying membranes. Nature 2016, 532, 480-483. [CrossRef] [PubMed]

6. Domènech, B.; Romero, V.; Vázquez, M.I.; Avila, M.; Benavente, J.; Muñoz, M.; Macanás, J. Chemical and electrochemical characterization of Nafion containing silver nanoparticles in a stripe-like distribution. RSC Adv. 2016, 6, 9923-9931. [CrossRef]

7. Ran, J.; Wu, L.; He, Y.; Yang, Z.; Wang, Y.; Jiang, C.; Ge, L.; Bakangura, E.; Xu, T. Ion exchange membranes: New developments and applications. J. Membr. Sci. 2017, 522, 267-291. [CrossRef]

8. Ma, J.; Sahai, Y. Chitosan biopolymer for fuel cell applications. Carbohydr. Polym. 2013, 92, 955-975. [CrossRef] [PubMed]

9. Maiti, J.; Kakati, N.; Lee, S.H.; Jee, S.H.; Viswanathan, B.; Yoon, Y.S. Where do poly(vinyl alcohol) based membranes stand in relation to Nafion ${ }^{\circledR}$ for direct methanol fuel cell applications? J. Power Sources 2012, 216, 48-66. [CrossRef]

10. García-Cruz, L.; Casado-Coterillo, C.; Iniesta, J.; Montiel, V.; Irabien, Á. Chitosan: Poly (vinyl) alcohol composite alkaline membrane incorporating organic ionomers and layered silicate materials into a PEM electrochemical reactor. J. Membr. Sci. 2016, 498, 395-407. [CrossRef]

11. Hyder, M.N.; Chen, P. Pervaporation dehydration of ethylene glycol with chitosan-poly(vinyl alcohol) blend membranes: Effect of CS-PVA blending ratios. J. Membr. Sci. 2009, 340, 171-180. [CrossRef]

12. Devi, D.A.; Smitha, B.; Sridhar, S.; Aminabhavi, T.M. Novel crosslinked chitosan/poly(vinylpyrrolidone) blend membranes for dehydrating tetrahydrofuran by the pervaporation technique. J. Membr. Sci. 2006, 280, 45-53. [CrossRef]

13. Guibal, E. Interactions of metal ions with chitosan-based sorbents: A review. Sep. Purif. Technol. 2004, 38, 43-74. [CrossRef]

14. Abiraman, T.; Ramanathan, E.; Kavitha, G.; Rengasamy, R.; Balasubramanian, S. Synthesis of chitosan capped copper oxide nanoleaves using high intensity $(30 \mathrm{kHz})$ ultrasound sonication and their application in antifouling coatings. Ultrason. Sonochem. 2017, 34, 781-791. [CrossRef] [PubMed]

15. De Godoi, F.C.; Rabelo, R.B.; da Cruz Vasconcellos, F.; Beppu, M.M. Preparation of copper nanoparticles in chitosan membranes and their application as irreversible humidity indicators. Chem. Eng. Trans. 2011, 24, 217-222. [CrossRef]

16. Elmezayyen, A.S.; Reicha, F.M. Preparation of chitosan copper complexes molecular dynamic studies of chitosan and chitosan copper complexes. Open J. Appl. Sci. 2015, 5, 415-427. [CrossRef]

17. Kickelbick, G. Concepts for the incorporation of inorganic building blocks into organic polymers on a nanoscale. Prog. Polym. Sci. 2003, 28, 83-114. [CrossRef]

18. Regiel, A.; Irusta, S.; Kyzioł, A.; Arruebo, M.; Santamaria, J. Preparation and characterization of chitosan-silver nanocomposite films and their antibacterial activity against Staphylococcus aureus. Nanotechnology 2013, 24, 015101. [CrossRef] [PubMed]

19. García-cruz, L.; Casado-coterillo, C.; Irabien, Á.; Montiel, V.; Iniesta, J. High performance of alkaline anion-exchange membranes based on chitosan/poly (vinyl) alcohol doped with graphene oxide for the electrooxidation. C J. Carbon Res. 2016, 2. [CrossRef]

20. Pérez-carvajal, J.; Lalueza, P.; Casado, C.; Téllez, C.; Coronas, J. Layered titanosilicates JDF-L1 and AM-4 for biocide applications. Appl. Clay Sci. 2012, 56, 30-35. [CrossRef]

21. Abu-Zied, B.M. $\mathrm{Cu}^{2+}$-acetate exchanged $\mathrm{X}$ zeolites: Preparation, characterization and $\mathrm{N}_{2} \mathrm{O}$ decomposition activity. Microporous Mesoporous Mater. 2011, 139, 59-66. [CrossRef]

22. Casado, C.; Ambroj, D.; Mayoral, Á.; Vispe, E.; Téllez, C.; Coronas, J. Synthesis, swelling, and exfoliation of microporous lamellar titanosilicate AM-4. Eur. J. Inorg. Chem. 2011, 2247-2253. [CrossRef]

23. Rubio, C.; Murillo, B.; Casado-Coterillo, C.; Mayoral, Á.; Téllez, C.; Coronas, J.; Berenguer-Murcia, Á.; Cazorla-Amorós, D. Development of exfoliated layered stannosilicate for hydrogen adsorption. Int. J. Hydrog. Energy 2014, 39, 13180-13188. [CrossRef] 
24. Higa, M.; Kobayashi, M.; Kakihana, Y.; Jikihara, A.; Fujiwara, N. Charge mosaic membranes with semi-interpenetrating network structures prepared from a polymer blend of poly(vinyl alcohol) and polyelectrolytes. J. Membr. Sci. 2013, 428, 267-274. [CrossRef]

25. Karas, F.; Hnát, J.; Paidar, M.; Schauer, J.; Bouzek, K. Determination of the ion-exchange capacity of anion-selective membranes. Int. J. Hydrogen Energy 2014, 39, 5054-5062. [CrossRef]

26. Ziv, N.; Mustain, W.E.; Dekel, D.R. The effect of ambient carbon dioxide on anion-exchange membrane fuel cells. ChemSusChem 2018, 11, 1136-1150. [CrossRef] [PubMed]

27. García-cruz, L.; Casado-Coterillo, C.; Iniesta, J.; Montiel, V.; Irabien, Á. Preparation and characterization of novel chitosan-based mixed matrix membranes resistant in alkaline media. J. Appl. Polym. Sci. 2015, 132, 42240. [CrossRef]

28. Franck-Lacaze, L.; Sistat, P.; Huguet, P.; Lapicque, F. Protonation and diffusion phenomena in poly(4-vinylpyridine)-based weak anion-exchange membranes. J. Membr. Sci. 2009, 340, 257-265. [CrossRef]

29. McHugh, T.H.; Avenabustillos, R.; Krochta, J.M. Hydrophilic Edible Films-Modified Procedure for Water-Vapor Permeability and Explanation of Thickness Effects. J. Food Sci. 1993, 58, 899-903. [CrossRef]

30. Hosseini, S.F.; Rezaei, M.; Zandi, M.; Farahmandghavi, F. Development of bioactive fish gelatin/chitosan nanoparticles composite films with antimicrobial properties. Food Chem. 2016, 194, 1266-1274. [CrossRef] [PubMed]

31. Simonelli, L.; Marini, C.; Olszewski, W.; Avila-Perez, M.; Ramanan, N.; Guilera, G.; Cuartero, V.; Klementiev, K. CLAESS: The hard X-ray absorption beamline of the ALBA CELLS synchrotron. Cogent Phys. 2016, 3, 1-10. [CrossRef]

32. Ravel, B.; Newville, M. ATHENA, ARTEMIS, HEPHAESTUS: Data analysis for X-ray absorption spectroscopy using IFEFFIT. J. Synchrotron Radiat. 2005, 12, 537-541. [CrossRef] [PubMed]

33. Dadachov, M.S.; Rocha, J.; Ferreira, A.; Lin, Z.; Anderson, M.W. Ab initio structure determination of layered sodium titanium silicate containing edge-sharing titanate chains (AM-4) $\mathrm{Na}_{3}(\mathrm{Na}, \mathrm{H}) \mathrm{Ti}_{2} \mathrm{O}_{2}\left[\mathrm{Si}_{2} \mathrm{O}_{6}\right] \cdot 2.2 \mathrm{H}_{2} \mathrm{O}$. Chem. Commun. 1997, 3, 2371-2372. [CrossRef]

34. Wang, X.; Wang, C. Chitosan-poly (vinyl alcohol)/ attapulgite nanocomposites for copper (II) ions removal: $\mathrm{pH}$ dependence and adsorption mechanisms. Colloids Surf. A Physicochem. Eng. Asp. 2016, 500, 186-194. [CrossRef]

35. Du, G.H.; van Tendeloo, G. $\mathrm{Cu}(\mathrm{OH})_{2}$ nanowires, $\mathrm{CuO}$ nanowires and $\mathrm{CuO}$ nanobelts. Chem. Phys. Lett. 2004, 393, 64-69. [CrossRef]

36. Domènech, B.; Muñoz, M.; Muraviev, D.N.; Macanás, J. Uncommon patterns in Nafion films loaded with silver nanoparticles. Chem. Commun. 2014, 50, 4693-4695. [CrossRef] [PubMed]

37. Anandan, S.; Lee, G.J.; Wu, J.J. Sonochemical synthesis of $\mathrm{CuO}$ nanostructures with different morphology. Ultrason. Sonochem. 2012, 19, 682-686. [CrossRef] [PubMed]

38. Shrivastava, B.D. X-ray absorption fine structure (XAFS) spectroscopy using synchrotron radiation. J. Phys. Conf. Ser. 2012, 365, 012002. [CrossRef]

39. Martini, A.; Borfecchia, E.; Lomachenko, K.A.; Pankin, I.A.; Negri, C.; Berlier, G.; Beato, P.; Falsig, H.; Bordiga, S.; Lamberti, C. Composition-driven Cu-speciation and reducibility in Cu-CHA zeolite catalysts: A multivariate XAS/FTIR approach to complexity. Chem. Sci. 2017, 8, 6836-6851. [CrossRef] [PubMed]

40. Borfecchia, E.; Lomachenko, K.A.; Giordanino, F.; Falsig, H.; Beato, P.; Soldatov, A.V.; Bordiga, S.; Lamberti, C. Revisiting the nature of $\mathrm{Cu}$ sites in the activated Cu-SSZ-13 catalyst for SCR reaction. Chem. Sci. 2015, 6, 548-563. [CrossRef] [PubMed]

41. Wu, H.; Zheng, B.; Zheng, X.; Wang, J.; Yuan, W.; Jiang, Z. Surface-modified Y zeolite-filled chitosan membrane for direct methanol fuel cell. J. Power Sources 2007, 173, 842-852. [CrossRef]

42. García-Cruz, L.; Casado-Coterillo, C.; Irabien, Á.; Montiel, V.; Iniesta, J. Performance assessment of a polymer electrolyte membrane electrochemical reactor under alkaline conditions-A case study with the electrooxidation of alcohols. Electrochim. Acta 2016, 206, 165-175. [CrossRef]

43. Palomino, G.T.; Fisicaro, P.; Bordiga, S.; Zecchina, A.; Giamello, E.; Lamberti, C. Oxidation States of Copper Ions in ZSM-5 Zeolites. A Multitechnique Investigation. J. Phys. Chem. B 2000, 104, 4064-4073. [CrossRef] [PubMed]

44. Geise, G.M.; Hickner, M.A.; Logan, B.E. Ionic resistance and permselectivity tradeoffs in anion exchange membranes. ACS Appl. Mater. Interfaces 2013, 5, 10294-10301. [CrossRef] [PubMed]

45. Bierhalz, A.C.K.; Moraes, Â.M. Tuning the properties of alginate-Chitosan membranes by varying the viscosity and the proportions of polymers. J. Appl. Polym. Sci. 2016, 133, 44216. [CrossRef] 
46. Alix, S.; Follain, N.; Tenn, N.; Alexandre, B.; Bourbigot, S.; Soulestin, J.; Marais, S. Effect of highly exfoliated and oriented organoclays on the barrier properties of polyamide 6 based nanocomposites. J. Phys. Chem. C 2012, 116, 4937-4947. [CrossRef]

47. El-Azzami, L.A.; Grulke, E.A. Carbon dioxide separation from hydrogen and nitrogen by fixed facilitated transport in swollen chitosan membranes. J. Membr. Sci. 2008, 323, 225-234. [CrossRef]

48. Lue, S.J.; Wang, F.J.; Hsiaw, S.Y. Pervaporation of benzene/cyclohexane mixtures using ion-exchange membrane containing copper ions. J. Membr. Sci. 2004, 240, 149-158. [CrossRef]

49. Zuo, G.; Wan, Y.; Wang, L.; Liu, C.; He, F.; Luo, H. Synthesis and characterization of laminated hydroxyapatite/chitosan nanocomposites. Mater. Lett. 2010, 64, 2126-2128. [CrossRef]

50. Choi, Y.J.; Song, J.H.; Kang, M.S.; Seo, B.K. Preparation and electrochemical characterizations of anion-permselective membranes with structurally stable ion-exchange sites. Electrochim. Acta 2015, 180, 71-77. [CrossRef]

51. Kikhavani, T.; Ashrafizadeh, S.N.; van der Bruggen, B. Identification of optimum synthesis conditions for a novel anion exchange membrane by response surface methodology. J. Appl. Polym. Sci. 2014, 131, 39888. [CrossRef]

52. Montgomery, D.C. Design and Analysis of Experiments, 4th ed.; Wiley: New York, NY, USA, 1997.

53. Giner-Sanz, J.J.; Ortega, E.M.; Pérez-Herranz, V. Statistical analysis of the effect of temperature and inlet humidities on the parameters of a semiempirical model of the internal resistance of a polymer electrolyte membrane fuel cell. J. Power Sources 2018, 381, 84-93. [CrossRef]

(C) 2018 by the authors. Licensee MDPI, Basel, Switzerland. This article is an open access article distributed under the terms and conditions of the Creative Commons Attribution (CC BY) license (http:/ / creativecommons.org/licenses/by/4.0/). 